\title{
NEUTRALIDADE E IMPARCIALIDADE? OS LIMITES DO MODELO PROCEDIMENTAL DE DEMOCRACIA
}

\author{
Neutrality and Imparciality? The limits of the procedural model of democracy
}

Diego Kosbiau Trevisan *

\begin{abstract}
Resumo: O objetivo desse artigo é discutir a ideia de democracia como procedimento em $\mathrm{J}$. Habermas e J. Rawls e apresentar algumas linhas críticas a essa teoria. Num primeiro momento exporemos o núcleo conceitual do modelo procedimental de democracia defendido por Habermas e Rawls e exposto, em suas convergências e divergências, nas discussões entre ambas ocorridas ao longo da década de 1990. Na sequência, delinearemos o caminho pelo qual trilharam as principais críticas a esse modelo, sobretudo no que diz respeito à figura do sujeito racional que lhe serve de pressuposto e que é posto em xeque pelos seus críticos.
\end{abstract}

Palavras-chave: Habermas, Rawls, Democracia, Imparcialidade, Procedimento.

\begin{abstract}
The aim of this paper is to discuss the idea of democracy as a procedure in J. Habermas and J. Rawls and present some criticisms about this theory. At first we expose the conceptual core of the procedural model of democracy advocated by Habermas and Rawls and exposed in the discussions between the two autors occurred during the 1990s, in which they make clear their agreements and disagreements. Further, we outline the main aspects of the criticisms to this whole model, especially with regard to the figure of rational subject in which it is based and which is called into question by its critics.
\end{abstract}

Keywords: Habermas, Rawls, Democracy, Impartiality, Procedure.

* Mestre em Filosofia pela Universidade de São Paulo (USP) e Doutorando em Filosofia pela USP e pela Johannes Gutenberg-Universität Mainz (JGU) - Bolsista FAPESP e DAAD - diegokosbiau@ hotmail.com.

\begin{tabular}{|c|c|c|c|c|c|}
\hline intuitio & $\begin{array}{c}\text { ISSN } \\
1983-4012\end{array}$ & Porto Alegre & Vol.8 $-\mathrm{N}^{\mathrm{o}} .1$ & $\begin{array}{c}\text { Junho } \\
2015\end{array}$ & p.246-260 \\
\hline
\end{tabular}




\section{Introdução}

Com o lançamento de "Facticidade e Validade" em 1992, Habermas apresentava de forma acabada sua teoria da democracia como procedimento, da qual esboços e estudos prévios vinham sendo continuamente formulados desde a primeira obra de vulto do autor, "Mudança Estrutural da Esfera Pública", publicada em 1962. Considerando que um ano após o surgimento de "Facticidade e Validade" John Rawls publicava seu "O Liberalismo Político", sedimentando ou modificando ideias fundamentais de sua teoria democrática inicialmente delineadas em "Uma Teoria da Justiça", de 1971, o autor ou comentador interessado em filosofia política - ou talvez de forma menos anacrônica, teoria política - vê o início da década de 90 como um período de farto material de análise e muito fecundo para o ideário democrático. O que parecia restar dessa pujança conceitual era um modelo bem acabado do processo democrático como um procedimento eticamente neutralizado e racionalmente motivado, apropriado para a reflexão sobre sociedades democráticas complexas que progressivamente se tornavam plurais e multiculturais e cada vez mais entravam em desacordo a respeito das normas sob as quais deviam ser regidas. Tal confiança desmedida no modelo procedimental, contudo, mostrou-se, de certa forma, ingênua. Não apenas em seu potencial explicativo de fenômenos sociais e políticos, mas mesmo em seus marcos estritamente conceituais e analíticos, a democracia como procedimento proposta por Rawls e Habermas expôs suas próprias fraquezas e suscitou críticas de diversas matizes, inclusive por parte daqueles teóricos que reconheciam seu valor no debate político contemporâneo. O objetivo desse artigo é apresentar de forma breve e sinóptica o núcleo conceitual da teoria desses dois autores e também delinear o caminho pelo qual trilharam as principais críticas a esse modelo procedimental de democracia.

Num primeiro momento, aproveitaremos o intercâmbio entre Habermas e Rawls, ocorrido logo após o lançamento das obras já mencionadas, para elucidar as características centrais do modelo procedimental, utilizando, sobretudo, as intuições centrais desse projeto expostas já em "Uma Teoria da Justiça". Desse produtivo confronto entre os dois autores, surgiram desavenças que ilustram de forma clara os pressupostos mais gerais da democracia como procedimento. Em sua crítica à tentativa rawlsiana de ancorar os princípios de justiça em uma determinada cultura política democrática, Habermas denuncia a "timidez" do projeto de Rawls, por este não ter apostado em uma fundamentação mais rigorosa a partir do "moral point of view" como ponto arquimediano de solução de conflitos em sociedades democráticas contemporâneas. Recusando um ponto de vista externo à teoria no seu intento de justificá-la e fundá-la, como, por exemplo, a referência a uma determinada cultura política. Habermas pretende encontrar nos pressupostos pragmáticos do discurso o almejado "moral point of view" na formulação de seu modelo deliberativo-procedimental de democracia (1). Essa opção, contudo, não sai ilesa das críticas. Segundo seus críticos, a teoria habermasiana da democracia como procedimento aceita princípios frágeis e controversos, cuja origem pode ser localizada na teoria da ação comunicativa que lhe serve de base

\begin{tabular}{|c|c|c|c|c|c|}
\hline intuitio & $\begin{array}{c}\text { ISSN } \\
1983-4012\end{array}$ & Porto Alegre & Vol.8 $-\mathrm{N}^{\circ} .1$ & $\begin{array}{c}\text { Junho } \\
2015\end{array}$ & p.246-260 \\
\hline
\end{tabular}


conceitual. Se nesta é empregada uma concepção de sujeito na qual a dimensão afetiva e do desejo é escamoteada ou ao menos reduzida a um papel secundário, nada mais natural que a teoria da democracia que dela se nutre padeça de deficiências na sua aplicação à realidade contemporânea das sociedades democráticas. Habermas, ao inflar a dimensão racional e apostar todas as suas fichas num consenso racionalmente motivado pouco presente na prática, oferece poucas ferramentas conceituais para a reflexão sobre os novos movimentos sociais e sobre a dinâmica motivacional dos conflitos políticos. Na melhor das hipóteses, Habermas tem diante de si a opção rawlsiana que fora previamente rejeitada por ele: apoiar-se numa cultura política democrática como estofo da teoria (2).

\section{Rawls e Habermas - Delineamentos do modelo procedimental}

O ponto de partida de Habermas e Rawls é, em linhas gerais, o mesmo: trata-se de fundar uma teoria da democracia em sociedades plurais sem com isso cair num relativismo ou ceder às críticas comunitaristas - a exigência que perpassa a obra desses teóricos é de imparcialidade e universalidade das normas que devem contar como públicas e, assim, acolher o assentimento de todos os seus endereçados envolvidos numa comunidade política democrática e heterogênea, sem, contudo, perder de vista o horizonte histórico concreto em que elas são formuladas. Segundo Habermas e Rawls - mas com significativas diferenças, como veremos - essa exigência somente pode ser satisfeita numa teoria procedimental da democracia, que abdica de razões substanciais e se apoia em procedimentos neutros e racionais de decisão política. Esse último movimento garantiria a almejada imparcialidade por não depender de visões de mundo determinadas e particulares e, inversamente, escorar-se num suposto "moral point of view" adotado por todos os participantes, ciosos de uma convivência política pacífica e conciliatória em sociedades democráticas contemporâneas.

Nessa seção, esboçaremos de forma bem sucinta a tese geral procedimental da democracia compartilhada por Habermas e Rawls. Num primeiro momento, discutiremos a teoria rawlsiana, sobretudo as alterações propostas no intervalo entre "Uma Teoria da Justiça" e "O Liberalismo Político" relativamente à dupla perspectiva de fundamentação dos princípios de justiça, a saber, um ancoramento político-histórico articulado com a idealização de um procedimento equitativo de decisão (a). Na sequência discutiremos as críticas de Habermas a Rawls, que basicamente giram em torno do decisivo recurso rawlsiano às convicções ponderadas dos cidadãos e à cultura política de determinada sociedade para justificar os princípios de justiça. Segundo Habermas, o deslocamento do "ônus conceitual" da teoria mesma para a cultura política em que esta deve ser aplicada traduz-se num "déficit normativo" que faz com que a teoria da justiça de Rawls se afaste do "moral point of view", por ambos, compartilhado (b). Tendo em vista as críticas habermasianas à solução "comunitarista" de Rawls, apresentaremos os

\begin{tabular}{|c|c|l|l|l|l|}
\hline intuitio & $\begin{array}{c}\text { ISSN } \\
1983-4012\end{array}$ & Porto Alegre & Vol.8 $-\mathrm{N}^{\mathrm{o}} .1$ & $\begin{array}{c}\text { Junho } \\
2015\end{array}$ & p.246-260 \\
\hline
\end{tabular}


contornos da teoria democrática de Habermas, recorrendo para tanto às intuições centrais da ética do discurso (c) ${ }^{1}$.

(a) O "2 Rawls", de "O Liberalismo Político", procurou fornecer uma solução de caráter duplo para o problema de fundamentação normativa em sociedades plurais democráticas contemporâneas. Segundo ele, a fundamentação de uma teoria democrática da justiça com pretensões normativas deve inevitavelmente buscar uma conciliação entre um momento "objetivo" (contextualização em situações histórico-sociais) e um "imparcial” (neutralidade dos princípios universais de justiça). Nessa medida, Rawls procurou primeiro dar "objetividade" ao momento da justificação, insistindo no modo como a "razão pública" deve estar ligada a uma sociedade bem-ordenada na qual se encontram atrelados certos valores comuns de uma cultura política pública, como, por exemplo, os de igualdade, liberdade, ausência de diferenças originárias de status, etc. ${ }^{2}$ Porém, ademais, estes princípios "substantivos" de justiça que foram escolhidos "aqui e agora" por cada cidadão foram também os mesmos que puderam passar por um "artifício representativo" ideal, um "procedimento" imparcial de tomada de decisão ${ }^{3}$. Se no primeiro momento a teoria garante a "objetividade" dos princípios, o segundo assegura a "imparcialidade" dos mesmos ${ }^{4}$.

O segundo momento de fundamentação, já presente em "Uma Teoria da Justiça", é aquele que deve garantir a universalidade e imparcialidade dos princípios de justiça, assegurando dessa forma a normatividade buscada, codificada, por seu turno, na divisa central da democracia como procedimento: "prioridade do justo sobre o bom", ou seja, a ideia de que os princípios de justiça servem como limite às concepções de bem individuais e à escolha dos caminhos para a realização destes ${ }^{5}$. A posição original,

\footnotetext{
${ }^{1}$ Para a análise dessa seção, seguimos em grande medida: MELO, R. S. O uso público da razão como procedimento: pluralismo, discurso e democracia em Habermas. São Paulo: USP, 2004. Dissertação (Mestrado em Filosofia). Faculdade de Filosofia e Ciências Humanas, Universidade de São Paulo, $1^{\circ}$ capítulo, pp. 16-66.

${ }^{2}$ Cf. RAWLS, J. O Liberalismo Político. São Paulo: Ed Ática, 2000, p. 50. "Nosso ponto de partida é (...) a noção da própria cultura pública como fundo comum de ideias e princípios básicos implicitamente reconhecidos. Esperamos formular essas ideias e princípios de forma clara o bastante para articulá-los em uma concepção política de justiça condizente com nossas convicções mais profundamente arraigadas".

${ }^{3}$ Essa exigência de imparcialidade dos princípios de justiça é expressa de modo mais enfático em Uma Teoria da Justiça. Segundo o " $1^{\circ}$ Rawls", a "posição original" conjugada com o "véu de ignorância", ou ainda esse "procedimento imparcial de formulação dos princípios de justiça", tem como objetivo "caracterizar essa situação de modo a que os princípios que são escolhidos, independentemente do que eles venham a ser, sejam aceitáveis a partir de um moral point of view. (...) Dessa forma, a justiça como equidade é capaz de usar desde seu início a idéia de justiça procedimental pura". RAWLS, J. A Theory of Justice. Cambridge: Harvard University Press, 1971, p. 120. Vale ressaltar que o artifício teórico da posição original e do véu de ignorância é mantido em $O$ Liberalismo Político.

${ }^{4}$ A título ilustrativo em nosso trabalho, os princípios de justiça conforme sua reformulação em $O$ Liberalismo Político são: "a. Todas as pessoas têm igual direito a um projeto inteiramente satisfatório de direitos e liberdades básicas iguais para todos, projeto este compatível com todos os demais; e, nesse projeto, as liberdades políticas, e somente estas, deverão ter seu valor eqüitativo garantido. b. As desigualdades sociais e econômicas devem satisfazer dois requisitos: primeiro, devem estar vinculadas a posições e cargos abertos a todos, em condições de igualdade eqüitativa de oportunidades; e, segundo, devem representar o maior benefício possível aos membros menos privilegiados da sociedade”. RAWLS, J. O Liberalismo Político. São Paulo: Ed Ática, 2000, pp. 47-8.

${ }_{5}^{5}$ RAWLS, J. A Theory of Justice. Cambridge: Harvard University Press, 1971, pp. 31-2.
}

\begin{tabular}{|c|c|c|c|c|c|}
\hline intuitio & $\begin{array}{c}\text { ISSN } \\
1983-4012\end{array}$ & Porto Alegre & Vol.8 $-\mathrm{N}^{\mathrm{o}} .1$ & $\begin{array}{c}\text { Junho } \\
2015\end{array}$ & p.246-260 \\
\hline
\end{tabular}


complementada pelo véu de ignorância, representa uma situação procedimental hipotética em que os indivíduos de uma sociedade bem ordenada são despidos de sua contextualização empírica e onde se apelam a duas "capacidades morais" dos mesmos: a racionalidade, isto é, a capacidade de perseguir fins, conceber e revisar as concepções de bem, e a razoabilidade, isto é, a capacidade de possuir um senso de justiça, de admitir e agir "pelos" princípios de justiça, ou seja, de submeter seus interesses próprios aos limites impostos pelos princípios de justiça ${ }^{6}$. Segundo Rawls, essa dupla perspectiva permite conceber uma cooperação social entre pessoas livres e iguais, que agem e se organizam numa sociedade regida por princípios de justiça escolhidos equitativamente na situação hipotética em que esse modelo abstrato de pessoa moral é utilizado. A posição original, lançando mão da primeira capacidade moral, a da racionalidade, alcança um primeiro momento de abstração, um ponto de vista não distorcido pelas configurações específicas da estrutura básica da sociedade concreta. O véu de ignorância vem completar esse processo abstrativo, despindo os indivíduos dos seus interesses e desejos concretos e colocando-os na situação equitativa <fair > de "pessoas livres e iguais"”. Somente assim, argumenta Rawls, é possível deliberar idealmente a respeito dos princípios normativos que devem reger uma sociedade bem ordenada. A segunda capacidade moral, o senso de justiça, por sua vez, tem como função garantir a estabilidade da cooperação, certificar de que os princípios de justiça adotados sejam de fato seguidos por todos.

Uma mudança significativa ocorrida no intervalo entre "Uma Teoria da Justiça” e "O Liberalismo Político" foi a progressiva importância que Rawls conferiu ao mencionado primeiro momento de fundamentação. Enquanto no início Rawls parecia apostar unicamente nos artifícios teóricos da posição original e do véu de ignorância, como fundamentos suficientes de seus princípios de justiça e nas duas capacidades morais do sujeito moral, em 1993, e na série de artigos que foram publicados entre seu primeiro grande livro e essa data, uma ancoragem política e cultural dos princípios imparciais de justiça mostrou-se necessária ao próprio Rawls ${ }^{8}$. No entanto, e Rawls é bem enfático nesse ponto, esse momento adicional de contextualização histórico-política dos princípios de justiça não pode ser interpretado como axiologicamente anterior ao momento de fundamentação racional, garantido pelos mecanismos procedimentais ideais, sob a pena de torná-los relativos e dependentes de conjunturas específicas e

\footnotetext{
${ }^{6}$ Cf. RAWLS, J. A Theory of Justice. Cambridge: Harvard University Press, 1971, pp 142-50; 407-16; 576. Cf. também RAWLS, J. "Kantian Constructivism in Moral Theory". In: Cambridge: Harvard University Press, 1999. Collected Papers. FREEMAN, S. (ed.).

${ }^{7}$ Cf. RAWLS, J. O A Theory of Justice. Cambridge. Harvard University Press, 1971, pp. 12-3.

${ }^{8} \mathrm{Na}$ introdução a "O Liberalismo Político", Rawls escreve que as mudanças fundamentais de sua teoria foram resultado da necessidade de explicitar e esclarecer o conceito de "estabilidade de uma sociedade bem ordenada", o que o teria levado a enfatizar a importância de um "consenso" prévio dos cidadãos a respeito de ideais e princípios compartilhados e fruto da cultura política na qual estão imersos, abdicando-se assim da "solução fraca" representada por um senso de justiça abstrato. Cf. RAWLS, J. Liberalismo Político. São Paulo: Ed Ática, 2000, p. 24. Embora Rawls negue explicitamente, a crítica comunitarista parece ter sido a causa dessa alteração no seu pensamento, e não tanto a coerência conceitual interna do problema da estabilidade.
}

\begin{tabular}{|c|c|c|c|c|c|}
\hline intuitio & $\begin{array}{c}\text { ISSN } \\
1983-4012\end{array}$ & Porto Alegre & Vol.8 $-\mathrm{N}^{\circ} .1$ & $\begin{array}{c}\text { Junho } \\
2015\end{array}$ & p.246-260 \\
\hline
\end{tabular}


historicamente datadas - ou ao menos é essa a pretensão de Rawls, que entretanto, como veremos agora, não fica livre da acusação de ter vacilado quanto à anterioridade do momento procedimental.

A leitura das conferências iniciais de "O Liberalismo Político" torna claro esse último ponto: aqui Rawls começa a esclarecer a ideia, discutida de forma mais detida na quarta conferência, de um consenso sobreposto, que pode ser descrito basicamente como a existência de um consenso social mínimo a respeito de certas questões fundamentais e relevantes para a comunidade política. Os diversos grupos sociais se põem de acordo sobre valores mínimos compartilhados ao mesmo tempo em que não abandonam suas próprias convicções e interesses, conservando apenas aqueles valores que podem coexistir pacificamente com os dos demais. Rawls caracteriza esse consenso como um consenso entre doutrinas abrangentes razoáveis em oposição a não-razoáveis ou irracionais, que não respeitam a divergência e procuram assim suprimir a existência de uma pluralidade. Como Rawls afirma, o "fato crucial não é o fato do pluralismo em si, mas do pluralismo razoável", que permite a coexistência de visões divergentes de mundo ${ }^{9}$. Por endossar uma concepção política comum que fomenta um pluralismo razoável, tal consenso sobreposto propicia, por exemplo, uma convivência pacífica entre crenças religiosas e morais divergentes em uma sociedade democrática plural. Segundo Rawls, essa noção de consenso sobreposto vem justamente resolver aquele problema da estabilidade social que o teria levado a modificar sua teoria original da justiça, ao acrescentar-lhe uma dimensão histórico-política mais espessa. O raciocínio é razoavelmente simples: a estabilidade implica que os cidadãos possam pôr-se de acordo a respeito de "fatos gerais que caracterizam a cultura política e pública de uma democracia"10, e a adesão dos cidadãos a tal cultura política e pública democrática que permite o pluralismo ocorre quando é "endossada como uma concepção moral" e quando "os cidadãos estão disposto a agir de acordo com ela com base em razões morais" ${ }^{11}$. Nessa perspectiva, as questões políticas fundamentais podem ser resolvidas recorrendo-se aos valores políticos expressos por tal concepção política e compartilhados por todas as doutrinas abrangentes razoáveis, solucionando-se, dessa forma, segundo Rawls, o problema de estabilidade da cooperação, ou em outras palavras, assegurando-se a possibilidade e a plausibilidade de um consenso entre os cidadãos a respeito dos princípios normativos de justiça em sociedades democráticas plurais ${ }^{12}$.

O que nos interessa aqui é o pressuposto contido ao longo de todo esse processo de fundamentação: há uma determinada cultura política democrática da qual se nutrem tais doutrinas

\footnotetext{
${ }^{9}$ RAWLS, J. Liberalismo Político. São Paulo: Ed Ática, 2000, p. 190.

${ }^{10}$ RAWLS, J. Liberalismo Político. São Paulo: Ed Ática, 2000, p. 187.

${ }^{11}$ RAWLS, J. Liberalismo Político. São Paulo: Ed Ática, 2000, p. 216.

12 Segundo Rawls, o consenso sobreposto resolve a segunda questão envolvida no problema da estabilidade; a primeira, que diz respeito a "se as passeas que crescem em meio a instituições justas (...) adquirem um senso de justiça suficiente, de modo a geralmente agirem de acordo com essas instituições", é respondida pela "exposição da psicologia moral, de acordo com a qual os cidadões de uma sociedade bem-ordenada adquirem um senso de justiça normalmente suficiente, de tal modo que agem de acordo com seus arranjos justos". RAWLS, J. Liberalismo Político. São Paulo: Ed Ática, 2000, p. 186.
}

\begin{tabular}{|c|c|c|c|c|c|}
\hline intuitio & $\begin{array}{c}\text { ISSN } \\
1983-4012\end{array}$ & Porto Alegre & Vol.8 $-\mathrm{N}^{\circ} .1$ & $\begin{array}{c}\text { Junho } \\
2015\end{array}$ & p.246-260 \\
\hline
\end{tabular}


abrangentes razoáveis, que molda a concepção de pessoa livre e igual presente na posição original e que, a rigor, se apresenta como instância limite do cotejo e possível revisão dos princípios de justiça supostamente escolhidos através de procedimentos idealizados. Como o próprio Rawls afirma, para "responder a uma questão fundamental como a da família de instituições mais apropriada para garantir a liberdade e a igualdade democrática (...), nosso ponto de partida é (...) a noção da própria cultura pública como fundo comum de ideias e princípios básicos implicitamente reconhecidos"13. Em suma, a democracia como cultura política concreta que permite a ideais políticos propiciadores de coesão e estabilidade social se introduz como ponto de fuga dos princípios aparentemente imparciais e universais escolhidos de forma procedimental - em poucas palavras, coloca-se em xeque a pretensa "neutralidade" e “imparcialidade" do procedimento. É justamente em torno desse último ponto que gira a crítica habermasiana a Rawls.

(b) O alvo da crítica de Habermas é o já por nós mencionado duplo nivelamento da justificação normativa presente na justiça como equidade rawlsiana. Segundo Habermas, o primeiro nível seria o de "fundamentação" stricto senso, representado pela posição original e pela constituição de um ponto de vista imparcial para o julgamento de questões ligadas à justiça política. O segundo nível seria o da "motivação" ou da estabilidade, que poria em questão a suficiência do procedimento imparcial para a justificação dos princípios de justiça adotados. Habermas vê aqui um emaranhamento conceitual interno entre o momento filosófico de justificação e o das condições extrafilosóficas de aceitação da teoria. Em suma, a coerência e o valor intrínseco e operacional da teoria seriam medidos através do recurso a "homens de carne e osso": "O teste com relação à neutralidade das visões de mundo dos conceitos basilares fundamentais se coloca sob outras premissas que não aquelas de uma revisão hipotética da capacidade reprodutiva de uma sociedade já instituída por meio de princípios de justiça. [...] Os princípios fundamentados no primeiro nível precisam ser submetidos publicamente à discussão no segundo nível, porque apenas aí se pode levar em consideração o fato do pluralismo e tornar retroativo o corte de abstração da posição original. Diante do fórum do uso público da razão a teoria em seu todo precisa ser exposta à crítica dos cidadãos; não se trata mais de cidadãos fictícios de uma sociedade justa, sobre os quais se podem emitir enunciados no interior da teoria, mas sim de cidadãos de carne e osso; a teoria precisa manter em aberto o desfecho de tal teste",14

Para Habermas, do embaralhamento de teoria e empiria resulta o enfraquecimento do ponto de vista imparcial que deveria ser axiologicamente anterior. Esse inadvertido nivelamento da justiça como

\footnotetext{
${ }^{13}$ RAWLS, J. Liberalismo Político. São Paulo: Ed Ática, 2000, p. 50.

${ }^{14}$ HABERMAS, J. "Versöhnung durch öffentlichen Vernunftgebrauch". In: Die Einbeziehung des Anderen - Studien zur politischen Theorie. Frankfurt. Suhrkamp, 1997a, p. 80. (Tradução brasileira: HABERMAS, J. A Inclusão do Outro - Estudos sobre teoria política. São Paulo: Loyola, 2002, p. 75). As citações das obras de Habermas são ligeiramente alteradas em relação às traduções disponíveis em português.
}

\begin{tabular}{|c|c|c|c|c|c|}
\hline intuitio & $\begin{array}{c}\text { ISSN } \\
1983-4012\end{array}$ & Porto Alegre & Vol.8 $-\mathrm{N}^{\circ} .1$ & $\begin{array}{c}\text { Junho } \\
2015\end{array}$ & p.246-260 \\
\hline
\end{tabular}


equidade introduz em seu cerne conceitual elementos substantivos de justiça que traem sua ambição procedimental e, assim, neutra de racionalidade política: “A revisão cognitiva de validação da teoria exige o deslocamento da perspectiva interna-formal - em que se encontra o 'corte de abstração' - para uma perspectiva não somente reflexiva, mas 'substantiva' - em que se encontram do lado de fora os cidadãos de carne e osso" "15. Menos dependente da concepção de razão prática e mais da cultura política em que estão imersos os "cidadãos de carne e osso", a teoria rawlsiana tardia da justiça "aponta para uma significativa mudança com que Rawls tratou o 'ponto de vista moral' imparcial. Ora, a própria razão prática que antes - na posição original - se nutria de uma concepção aparentemente neutra de 'pessoa moral', passa a se nutrir de valores políticos compartilhados numa sociedade democrática e liberal, fazendo com que houvesse um enfraquecimento das pretensões racionais de uma concepção kantiana de justiça na estrutura interna da teoria"16. A ancoragem histórico-política sufoca as pretensões universalistas da filosofia de Rawls, induzindo a comentários como o de Richard Rorty, para quem o pensamento rawlsiano é o exemplo mais bem acabado da cultura democrática norte-americana da segunda metade do século XX - um, digamos, paradoxal “comunitarista kantiano", e nada além disto ${ }^{17}$.

Como, contudo, Habermas poderá escapar a esse desanimador vaticínio? Como será possível a ele situar em um contexto histórico determinado sua teoria procedimental sem perder de vista a prevalência do ponto de vista imparcial que funda a universalidade do procedimento?

(c) Como já vimos notando, Habermas aceita uma série de intuições rawlsianas presentes já em Uma Teoria da Justiça : o procedimento deve ser neutro e imparcial, ou seja, deve basear-se num “moral point of view" universal de matiz kantiana, o que significa, entre outras coisas, aceitar a anterioridade do justo sobre o bom. "Neutralidade significa, em primeiro lugar, que o justo, fundamentado na lógica da argumentação, tem o primado sobre o bom, ou seja, que as questões relativas à vida boa cedem o lugar às questões da justiça" ${ }^{\text {"18 }}$. Aqui já vemos tanto a filiação habermasiana ao projeto de Rawls quanto a diferença fundamental que os opõe: se é fato que ambos aceitam o primado do justo sobre o bom (isto é, a anterioridade axiológica da concepção política da sociedade relativamente às várias doutrinas abrangentes

\footnotetext{
${ }^{15}$ MELO, R. S. O uso público da razão como procedimento: pluralismo, discurso e democracia em Habermas. São Paulo: USP, 2004. Dissertação (Mestrado em Filosofia). Faculdade de Filosofia e Ciências Humanas, Universidade de São Paulo, p. 38.

${ }^{16}$ MELO, R. S. O uso público da razão como procedimento: pluralismo, discurso e democracia em Habermas. São Paulo: USP, 2004. Dissertação (Mestrado em Filosofia). Faculdade de Filosofia e Ciências Humanas, Universidade de São Paulo, p. 38.

${ }^{17}$ Habermas expressa essa idéia da usando a figura de uma "feliz convergência de imagens de mundo": "A validade moral da concepção de justiça já não se fundamenta a partir de uma razão prática que obriga universalmente, mas sim a partir de uma feliz convergência de imagens de mundo razoáveis que se justapõem de forma suficiente em seus componentes morais". HABERMAS, J. Die Einbeziehung des Anderen - Studien zur politischen Theorie. Frankfurt. Suhrkamp, 1997, p. 104. (Tradução brasileira: HABERMAS, J. A Inclusão do Outro - Estudos sobre teoria política. São Paulo: Loyola, 2002, p. 98).

${ }^{18}$ HABERMAS, J. Faktizität und Geltung. Frankfurt: Suhrkamp, 1998, p. 375. (Tradução brasileira: HABERMAS, J. Direito e democracia: entre facticidade e validade. 2 Vols. Rio de Janeiro. Tempo Brasileiro, 1997b, v. II, p. 35).
}

\begin{tabular}{|c|c|c|c|c|c|}
\hline intuitio & $\begin{array}{c}\text { ISSN } \\
1983-4012\end{array}$ & Porto Alegre & Vol.8 $-\mathrm{N}^{\circ} .1$ & $\begin{array}{c}\text { Junho } \\
2015\end{array}$ & p.246-260 \\
\hline
\end{tabular}


presentes nesta), Habermas, por seu turno, busca fundamentar tal primado - e, no limite, toda sua teoria procedimental da democracia - numa lógica da argumentação, e não na "feliz concordância de imagens de mundo" inscritas numa cultura política determinada, como ocorria em Rawls.

Somente pelo caminho de uma ética do discurso Habermas crê ser possível salvar o "moral point of view" tido por ambos como central no esforço de fundar uma teoria normativa de justiça em sociedades plurais: "Se quisermos salvar a intuição do princípio kantiano de universalização, poderemos reagir a esse fato do pluralismo de diferentes maneiras. Pela limitação da informação, Rawls fixa as partes da posição original numa perspectiva comum e neutraliza assim de antemão, mediante um artifício, a multiplicidade das perspectivas particulares de interpretação. A ética do discurso, pelo contrário, vê o ponto de vista moral como incorporado no procedimento de uma argumentação conduzida intersubjetivamente, que exorta os participantes a erguerem as barreiras <Entschränkung> idealizadas de suas perspectivas de interpretação" ${ }^{19}$. Segundo Habermas, o ponto de vista moral imparcial deve ser acolhido por todos os participantes concretos na interação comunicativa sem a necessidade de hipostasiar uma situação fictícia de deliberação; em outras palavras, os interessados têm em vista a imparcialidade da norma ao avaliar e medir as consequências efetivas e o interesse que a mesma possui para todos: "É imparcial apenas o ponto de vista a partir do qual são capazes de universalização exatamente aquelas normas que, por incorporarem reconhecidamente o interesse geral de todos os concernidos, podem contar com um assentimento $<$ Zustimmung $>$ universal - e, por isso, merecem reconhecimento intersubjetivo" ${ }^{20}$. Habermas, assim, tenta unir os dois momentos de fundamentação em apenas um só: não mais há um procedimento idealizado (posição original) oposto a uma situação concreta (cultura política), mas antes ambos estão inscritos na própria estrutura argumentativa que, ela mesma, mede as pretensões normativas dos princípios sugeridos no cotejo com o interesse dos participantes, tomados agora como parceiros racionais do discurso que levantam reivindicações e não mais como "pessoas morais abstratas" ou "extrateóricos "cidadãos de carne e osso"”.

Para Habermas, a natureza reflexiva do processo não depende de um "consenso sobreposto" calcado numa dimensão que extrapola a teoria, mas antes está inserida na dinâmica mesma da argumentação com vistas ao entendimento recíproco, a qual, por seu turno, se reflete nos mecanismos reais em que esta toma lugar nas sociedades democráticas contemporâneas. Em suma, uma racionalidade plenamente procedimental entra no lugar da cultura política compartilhada como lócus de justificação normativa de princípios fundamentais de justiça, dentre eles a autonomia privada do cidadão, codificada

\footnotetext{
${ }^{19}$ HABERMAS, J. Die Einbeziehung des Anderen - Studien zur politischen Theorie. Frankfurt. Suhrkamp, 1997a, p. 75. (Tradução brasileira: HABERMAS, J. A Inclusão do Outro - Estudos sobre teoria política. São Paulo: Loyola, 2002, p. 71).

${ }^{20}$ HABERMAS, J. "Diskursethik - Notizen zu einem Begründungsprogram". In: HABERMAS, J. Moralbewusstsein und kommunikatives Handeln. Frankfurt: Suhrkamp, 1983, p. 75. (Tradução brasileira: HABERMAS, J. Consciência moral e agir comunicativo. Rio de Janeiro: Tempo Brasileiro, 1989, p. 86).
}

\begin{tabular}{|c|c|c|c|c|c|}
\hline intuitio & $\begin{array}{c}\text { ISSN } \\
1983-4012\end{array}$ & Porto Alegre & Vol. $-\mathrm{N}^{\circ} .1$ & $\begin{array}{c}\text { Junho } \\
2015\end{array}$ & p.246-260 \\
\hline
\end{tabular}


nos direitos fundamentais intangíveis à propriedade, segurança, etc., e a autonomia pública, representada pelo direito à participação política e à interferência argumentativa nos negócios públicos - segundo Habermas, o respeito a essa dupla exigência de autonomia estaria presente nas condições de possibilidade de um discurso comunicativo voltado ao consenso e à justificação racional de normas, ou seja, na suposição de paridade de participação e de intangibilidade pessoal na formulação e defesa dos interesses próprios $^{21}$.

Como é comum em sua vasta obra, a pretensão habermasiana aqui não é pequena: com sua teoria procedimental da democracia, Habermas pretende superar a tradicional dicotomia entre "liberdade dos antigos" e "liberdade dos modernos", ou ainda, a oposição entre a "solução liberal-lockeana" e a "solução republicana-rousseauísta" para a teoria democrática ${ }^{22}$. Segundo ele, o modelo liberal de democracia (que se apoia na autonomia privada, isto é, na defesa de liberdades fundamentais pré-existentes à instauração do Estado e que, assim, servem de limite à atuação deste) se articularia com o modelo republicano de democracia (que tem como base a autonomia pública, isto é, a exigência de autodeterminação ética da comunidade nas decisões sobre prioridades jurídicas e políticas) justamente no interior de um modelo deliberativo-procedimental de democracia baseado nos princípios da ética do discurso: "A teoria do discurso assimila elementos de ambos os lados [liberal e republicano], integrando-os no conceito de um procedimento ideal para a deliberação e a tomada de decisão. Esse processo democrático estabelece um nexo interno entre considerações pragmáticas, compromissos, discursos de autoentendimento e discursos da justiça, fundamentando a suposição de que é possível chegar a resultados racionais e equitativos. Nesta linha, a razão prática passa dos direitos humanos universais ou da eticidade concreta de uma determinada comunidade para as regras do discurso e as formas de argumentação, que extraem seu conteúdo normativo da base de validade do agir orientado pelo entendimento e, em última instância, da estrutura da comunicação linguística e da ordem insubstituível da socialização comunicativa" ${ }^{\text {23 }}$. Como vimos o modelo procedimental calcado na racionalidade comunicativa "fundaria" a "suposição de que é possível chegar a resultados racionais e equitativos" - em outras palavras, séculos de debate político seriam solucionados unicamente com o recurso aos "inevitáveis" pressupostos comunicativos da teoria da ação comunicativa

21 Sobre isso, cf. HABERMAS, J. "Volkssouveränität als Verfahren". In: Faktizität und Geltung. Frankfurt: Suhrkamp, 1998. (Tradução brasileira: HABERMAS, J. "A soberania popular como procedimento". In: Direito e democracia: entre facticidade e validade. 2 Vols. Rio de Janeiro. Tempo Brasileiro, 1997, Vol. II) e HABERMAS, J. "Der demokratische Rechtsstaat - eine paradoxe Verbindung widersprüchlicher Prinzipien?" In: . Zeit der Übergänge. Frankfurt: Suhrkamp, 2001, esp. pp. 147ss. (Tradução brasileira: HABERMAS, J. "O Estado democrático de direito - uma amarração paradoxal de princípios contraditórios?” In: Era das transições. Rio de Janeiro: Tempo Brasileiro, 2003, esp. pp. 167ss).

${ }^{22}$ HABERMAS, J. "Drei normative Modelle der Demokratie". In:____. Die Einbeziehung des Anderen - Studien zur politischen Theorie. Frankfurt. Suhrkamp, 1997. (Tradução brasileira: HABERMAS, J. "Três modelos normativos de democracia". In: . A Inclusão do Outro - Estudos sobre teoria política. São Paulo: Loyola, 2002).

${ }^{23}$ HABERMAS, J. Faktizität und Geltung. Frankfurt: Suhrkamp, 1998, p. 359. (Tradução brasileira: HABERMAS, J. Direito e democracia: entre facticidade e validade. 2 Vols. Rio de Janeiro. Tempo Brasileiro, $1997 \mathrm{~b}$, v. II, p. 19.

\begin{tabular}{|c|c|c|c|c|c|}
\hline intuitio & $\begin{array}{c}\text { ISSN } \\
1983-4012\end{array}$ & Porto Alegre & Vol.8 $-\mathrm{N}^{\circ} .1$ & $\begin{array}{c}\text { Junho } \\
2015\end{array}$ & p.246-260 \\
\hline
\end{tabular}


habermasiana. O problema agora parece voltar-se a essa suposição adicional: seria a ética do discurso habermasiana aceitável sem maiores e problemáticas pressuposições? A sua confiança excessiva na "racionalidade" dos participantes do discurso não seria ingênua? A resposta negativa a essas perguntas conduziria à desconfiança no "moral point of view" e, por consequência, em todo o modelo procedimental de democracia.

\section{Críticas ao Modelo procedimental - contra o sujeito racional e transparente}

A título ilustrativo, podemos classificar as críticas ao modelo procedimental de democracia em dois grupos distintos: por um lado, há a crítica gestada no interior do movimento feminista norteamericano, que acusa a existência de um "gender bias" nas teorias de Habermas e Rawls e opõe-lhes um modelo de sujeito político não baseado no ideal de um "homem branco heterossexual" "24; por outro, há os atuais teóricos da teoria crítica, que descreem no potencial conciliatório do procedimento neutralizado e pregam uma discreta "substancialização" dos princípios de justiçaa 25 . Para ambos, contudo, é comum a condenação da supervalorização da busca por um consenso racionalmente motivado como inscrito na estrutura mesma da discussão política (Rawls) ou da argumentação (Habermas) - em suma, é a própria figura do "sujeito racional" que é posta em questão. Vejamos de forma sinóptica a crítica a Habermas especificamente.

Habermas crê que sua teoria da democracia como procedimento é o remédio para o problema do pluralismo de formas de vida, isto é, para aqueles conflitos aparentemente incomensuráveis em sociedades democráticas contemporâneas, solucionados através do princípio de universalização da ética do discurso ancorado num intercâmbio argumentativo. O problema, contudo, retorna à sua formulação inicial: se do procedimento de universalização devem resultar normas cujas consequências vislumbradas satisfazem os interesses dos participantes, nada é dito ou resolvido a respeito do fato de que são os interesses mesmos que são conflitantes e que, assim, impedem desde o início o acordo racional e consensual acerca das consequências da norma ${ }^{26}$. A própria ideia de imparcialidade que guia o procedimento de universalização é posta em xeque por esse conflito originário de interesses - sem que os participantes do discurso ponham-

\footnotetext{
${ }^{24}$ Cf. YOUNG, I. M. "Impartiality and Civil Public: Some Implications of Feminism Critiques of Moral and Political Philosophy". In: BENHABIB, S. \& CORNELL, D. (eds). Feminism as Critic. Minneapolis: University of Minnesota, 1987, bem como os artigos contidos no volume: MEEHAN, J (ed). Feminists Read Habermas. New York \& London: Routledge, 1995. Especialmente sobre as críticas feitas aqui, cf. DEAN, J. "Discourse in Different Voices". pp. 205-29.

${ }^{25}$ Dentre os atuais expoentes da teoria crítica que questionam o modelo estritamente procedimental habermasiano de justiça, os principais são Axel Honneth (principalmente em: Kampf um Anerkennung. Frankfurt: Suhrkamp, 1992. Tradução brasileira: Luta por Reconhecimento. São Paulo. Editora 34, 2002) e Rainer Forst (Kontexte der Gerechtigkeit. Frankfurt: Suhrkamp, 1996).

${ }^{26}$ McCARTHY, T. "Practical Discourse: On the Relation of Morality to Politics". In: CALHOUN, C. (ed). Habermas and the Public Sphere. Cambridge: The MIT Press, 1996, p. 59.
}

\begin{tabular}{|c|c|l|l|l|l|}
\hline intuitio & $\begin{array}{c}\text { ISSN } \\
1983-4012\end{array}$ & Porto Alegre & Vol.8 $-\mathrm{N}^{\mathrm{o}} .1$ & $\begin{array}{c}\text { Junho } \\
2015\end{array}$ & p.246-260 \\
\hline
\end{tabular}


se de acordo sobre seus interesses, nenhum ponto de vista moral imparcial e neutro se lhes apresenta como possível.

Chegamos aqui a um dilema central da ética do discurso habermasiana: se interesses, sentimentos, desejos são incomensuráveis, isto é, se não é possível chegar a um acordo sobre a "cogência” de razões nesse campo, então a argumentação, supostamente racional, confunde-se com a retórica ${ }^{27}$. Isso é consequência direita da interpretação habermasiana de Freud: para Habermas, os atos inconscientes de comportamento descritos por Freud seriam passíveis de tornarem-se conscientes mediante um gradual processo terapêutico.

Em todos esses casos, mesmo se nós garantirmos que é possível em princípio trazer à consciência qualquer fator particular inconsciente, isso não implica absolutamente a possibilidade de torná-los todos conscientes de uma só vez. Porém, isso significa que a todo momento e em qualquer situação fatores inconscientes desempenham um papel na formação de perspectivas avaliativas e interpretativas, e dessa forma a força simbólica da linguagem irá inevitavelmente figurar nos juízos de cogência ${ }^{28}$.

Abdicando-se das figuras habermasianas de sujeito e de linguagem resulta a ausência de um ponto arquimediano a partir do qual julgar os diversos interesses dos membros da sociedade, restando apenas um contínuo debate permeado por razões "lógico-argumentativas" e retóricas. O ideal de consenso em temas

27 “Ademais, se juízos sobre a relativa cogência <cogency> de razões que citam necessidades, interesses, sentimentos, sensações, e assim por diante, variam com os diferentes pontos de vistas avaliativos e interpretativos, e se não há uma medida comum a partir da qual avaliar os pesos relativos de razões articuladas em diferentes linguagens avaliativas, então a distinção entre argumento e retórica, entre convencer e persuadir torna-se menos marcada do que permite o modelo do discurso". McCARTHY, T. "Practical Discourse: On the Relation of Morality to Politics". In: CALHOUN, C. (ed). Habermas and the Public Sphere. Cambridge: The MIT Press, 1996, p. 64.

${ }^{28}$ McCARTHY, T. "Practical Discourse: On the Relation of Morality to Politics". In: CALHOUN, C, (ed). Habermas and the Public Sphere. Cambridge: The MIT Press, 1996, p. 64. Sobre a apropriação habermasiana de Freud, ver: MacKENDRICK, K. Discourse, Desire, and Fantasy in Jürgen Habermas' Critical Theory. New York \& London: Routledge, 2008, esp. caps. 2 e 3. "Para Habermas, a psicanálise, interpretada por meio de uma teoria da linguagem, é uma disciplina crítica e auto-reflexiva com potencial para colocar-se atrás das distorções comunicativas e, ao mesmo tempo, fornecer uma reconstrução teórica das relações comunicativas ideais. Habermas argumenta que Freud implicitamente se apoia no ideal de uma fala não distorcida no interior da situação analítica. Habermas permanece fiel a esse ideal ao torná-lo explícito, e busca então fornecer uma justificação racional para ele de modo a conferir base normativa à teoria crítica. O ideal-guia de uma comunicação não distorcida e a visada reconstrutiva de Habermas permanecem constantes em sua obra. O ideal é capturado numa variedade de expressões em seus escritos: comunicação livre de coerção, a comunidade comunicativa ilimitada, as situações ideais de fala, comunicação sem barreiras, comunicação livre de distorções, fala não distorcida, intersubjetividade não danificada, e assim por diante". MacKendrick, (2008), p. 52. Como se vê, a interpretação habermasiana de Freud retém o ideal de uma fala sem distorções, obtida por um processo reflexivo em que os sujeitos, em suas relações intersubjetivas, gradualmente se poriam a nu um frente ao outro, tornando transparentes suas exigências de veracidade, verdade e correção normativa. Somente ao negar a dimensão eminentemente descritiva do sujeito e advogar a possibilidade de uma racionalidade perfeita é que Habermas pode defender algo como um ponto de vista moral neutro e imparcial, e, assim, uma democracia como um procedimento moralmente não comprometido, em que o elemento volitivo e afetivo desaparece "nos resultados". Para a interpretação habermasiana da psicanálise, ver as obras iniciais do autor: HABERMAS, J. Zur Logik der Sozialwissenschaften. Frankfurt: Suhrkamp, 1982. (Tradução brasileira: HABERMAS, J. Sobre a Lógica das Ciências Sociais. São Paulo: Vozes, 2009) e HABERMAS, J. Erkenntniss und Interesse. Frankfurt: Suhrkamp, 1962. (Tradução brasileira: HABERMAS, J. Conhecimento e Interesse. Rio de Janeiro: Zahar, 1982).

\begin{tabular}{|c|c|c|c|c|c|}
\hline intuitio & $\begin{array}{c}\text { ISSN } \\
1983-4012\end{array}$ & Porto Alegre & Vol.8 $-\mathrm{N}^{\mathrm{o}} .1$ & $\begin{array}{c}\text { Junho } \\
2015\end{array}$ & p.246-260 \\
\hline
\end{tabular}


político-práticos torna-se faticamente comprometido, deixando de servir como único modelo a instituições democráticas - o "moral point of view" torna-se apenas mais um dentre outros ${ }^{29}$.

Em suma, Habermas sustenta o ideal de um indivíduo plenamente transparente, permeado por fluxos linguísticos comunicativos que o colocariam numa pacífica comunhão racional-argumentativa com outros falantes, com os quais poderia então atingir acordos e consensos racionalmente motivados. Tal assunção é sustentável de um ponto de vista psicanalítico? Esse ideal utópico de uma comunidade linguística pode se apoiar apenas nos pressupostos pragmáticos do discurso ou nas idealizações das pretensões racionais dos atos de fala sem, ao mesmo tempo, depender fundamentalmente de uma concepção de "indivíduo", "sujeito", "psique” altamente questionável de um ponto de vista "clínico”? Não se pretende com isso considerar como "errada" ou "falsa" a teoria habermasiana, mas apenas indicar como há uma "pressuposição fundamental” em sua base, similar àquela por ele denunciada em Rawls.

Quando se vê diante desses problemas, Habermas parece de fato flertar com um "pragmatismo" no momento de fundamentar sua teoria democrática. Na sua resposta à crítica de McCarthy de que a sociedade política estaria perpassada por conflitos éticos e de valor que impediriam a adoção de um ponto de vista imparcial e neutro para a resolução desses conflitos incomensuráveis, Habermas opõe sua solução consensual àqueloutra que se deixa concluir a partir dos argumentos de McCarthy, a saber, a alternativa de Carl Schmitt sobre a compreensão da política como um mero "decisionismo"30. Os pressupostos pragmáticos do discurso, as idealização dos atos de fala, etc., parecem se mostrar insuficientes para justificar o modelo deliberativo da democracia como procedimento em face de sociedades multiculturais em que orientações valorativas contraditórias conflitam. A solução aparente de Habermas é a "pressuposição" de que a política pode almejar um consenso sobre questões controversas como alternativa à concepção schmittiana de política como processos conciliatórios estratégicos e temporários, que tornam a legitimação algo empiricamente obtido ${ }^{31}$. Essa saída habermasiana torna-se explicita em "Facticidade $e$

\footnotetext{
${ }^{29}$ Segundo Iris Marion Young, a teoria da ação comunicativa de Habermas aceita o velho esquema presente na filosofia moral que opõe razão a desejo, escamoteando os aspectos afetivos da esfera normativa de decisões políticas. "Eu sugiro (...) que esse modelo de comunicação [habermasiano] reproduz a oposição entre razão e desejo, pois, a exemplo da razão normativa moderna, ele expele e desvaloriza a diferença: a concretude do corpo, os aspectos afetivos da fala, os aspectos figurativos e musicais de todos os enunciados e que contribuem para a formação e entendimento de seu significado". YOUNG, I. M. "Impartiality and Civil Public: Some Implications of Feminism Critiques of Moral and Political Philosophy". In: BENHABIB, S. \& CORNELL, D. (eds). Feminism as Critic. Minneapolis: University of Minnesota, 1987, p. 71. Como resultado, ela avalia que a teoria política que surge daí inevitavelmente torna recluso o que escapa de sua "ânsia racionalista": "A razão normativa moderna e sua expressão política na idéia de um público civil, então, tem unidade e coerência pela expulsão e confinamento de tudo que ameaçaria invadir a política com diferenciação: a especificidade dos corpos femininos e o desejo, a diferença de raça e cultura, a variabilidade e heterogeneidade das necessidades, os objetivos e desejos de cada indivíduo, a ambiguidade e instabilidade do sentimento" (p. 67).

${ }^{30}$ Cf. HABERMAS, J. Die Einbeziehung des Anderen - Studien zur politischen Theorie. Frankfurt. Suhrkamp, 1997a, pp. 298ss. (Tradução brasileira: HABERMAS, J. A Inclusão do Outro - Estudos sobre teoria política. São Paulo: Loyola, 2002, p. 315ss).

${ }^{31}$ HABERMAS, J. Die Einbeziehung des Anderen - Studien zur politischen Theorie. Frankfurt. Suhrkamp, 1997a, p.
}

\begin{tabular}{|c|c|l|l|l|l|}
\hline intuitio & $\begin{array}{c}\text { ISSN } \\
1983-4012\end{array}$ & Porto Alegre & Vol.8 $-\mathrm{N}^{\mathrm{o}} .1$ & $\begin{array}{c}\text { Junho } \\
2015\end{array}$ & p.246-260 \\
\hline
\end{tabular}


Validade": "Se quisermos enfrentar questões que tratam da regulação de conflitos ou da persecução de fins coletivos sem empregar a alternativa dos conflitos violentos, temos que adotar uma prática de entendimento, cujos processos e pressupostos comunicativos, no entanto, não se encontram simplesmente à nossa disposição" $" 32$.

No fundo Habermas parece recorrer à mesma solução de Rawls - há uma cultura política compartilhada e eticamente não-neutra que oferece um fundo comum interpretativo para a esfera pública. O que Habermas não menciona é a possível função que essa cultura política pode exercer como "antídoto" à alternativa schmittiana: em sociedades plurais, democráticas e pós-autoritárias, é natural que a cultura política compartilhada incentive a busca pelo consenso, até, é claro, que circunstâncias eventualmente conduzam a uma mudança nessa perspectiva ${ }^{33}$. A saída de Habermas é o recurso a um "patriotismo constitucional" que fornece a motivação para o respeito aos direitos fundamentais em sua ligação com a soberania popular, mas que, segundo Habermas, não pode revogar a neutralidade ética da ordem jurídica. Esse "patriotismo constitucional", em conjunto com o universalismo do procedimento, o "consenso procedimental", deve marcar a universalidade e a neutralidade da ordem jurídica e a busca por um consenso duradouro em questões políticas e constitucionais ${ }^{34}$ - e tudo isso, decerto, apoiado na concepção de sujeito adotada pela ética do discurso, sobre o qual, contudo, Habermas não se pronuncia ou ressalta ser uma "pressuposição inevitável" de seu modelo.

Seria o "patriotismo constitucional" e o recurso à "cultura política democrática" de "sujeitos racionais e plenamente transparentes" suficientes para compreender as reivindicações dos novos movimentos sociais ou para dar conta da efetiva dinâmica política presente nos conflitos sociais em geral? Não cremos. Embora apresentem elementos conceituais centrais e paradigmáticos do cenário políticofilosófico da segunda metade do séc. XX, as teorias procedimentais da democracia realizam um alijamento da esfera afetiva e do desejo da esfera pública que parece ter como resultado tanto o recrudescimento do interesse na participação efetiva em assuntos políticos, reduzidos como estão a um

308. (Tradução brasileira: HABERMAS, J. A Inclusão do Outro - Estudos sobre teoria política, São Paulo: Loyola, 2002, p. 326).

${ }^{32}$ HABERMAS, J. Faktizität und Geltung. Frankfurt: Suhrkamp, 1998, p. 376. (Tradução brasileira: HABERMAS, J. Direito e democracia: entre facticidade e validade. 2 Vols. Rio de Janeiro. Tempo Brasileiro, 1997, v. II, p. 36).

${ }_{33}$ Cf. sobre a cultura política democrática: HABERMAS, J. Die Einbeziehung des Anderen - Studien zur politischen Theorie. Frankfurt. Suhrkamp, 1997, p. 360. (Tradução brasileira: HABERMAS, J. A Inclusão do Outro - Estudos sobre teoria política. São Paulo: Loyola, 2002, p. 254).

${ }^{34}$ Cf. HABERMAS, J. Die Einbeziehung des Anderen - Studien zur politischen Theorie. Frankfurt. Suhrkamp, 1997a, p. 361. (Tradução brasileira: HABERMAS, J. A Inclusão do Outro - Estudos sobre teoria política. São Paulo: Loyola, 2002, p. 255). Sobre isso, cf. também HABERMAS, J. "Der demokratische Rechtsstaat - eine paradoxe Verbindung widersprüchlicher Prinzipien?” In: ___ Zeit der Übergänge. Frankfurt: Suhrkamp, 2001, p. 144. (Tradução brasileira: HABERMAS, J. "O Estado democrático de direito - uma amarração paradoxal de princípios contraditórios?” In: ___ _. Era das transições. Rio de Janeiro: Tempo Brasileiro, 2003, p. 165), em que Habermas refaz esse mesmo argumento, agora na tentativa de interromper o círculo vicioso ou o regresso ao infinito na fundamentação daquilo que fundamenta o procedimento.

\begin{tabular}{|c|c|c|c|c|c|}
\hline intuitio & $\begin{array}{c}\text { ISSN } \\
1983-4012\end{array}$ & Porto Alegre & Vol.8 $-\mathrm{N}^{\mathrm{o}} .1$ & $\begin{array}{c}\text { Junho } \\
2015\end{array}$ & p.246-260 \\
\hline
\end{tabular}


plano asséptico, quanto o surgimento de patologias sociais, seja na esfera pública seja mesmo na esfera privada, advindas do "recalque" da dimensão afetiva exigido pela sociedade "bem ordenada" e pelo "consenso racionalmente motivado" - o livre curso aos desejos, removido da interação social e política aceita, pode ser redirecionado à esfera íntima de forma perversa, ou à esfera política sob a forma de conluios, nepotismos, favorecimento pessoal, etc.. "Outro da razão" parece mais uma vez entrar pela porta dos fundos.

\section{Referências}

FORST, R. Kontexte der Gerechtigkeit. Frankfurt: Suhrkamp, 1996.

HABERMAS, J. A Inclusão do Outro - Estudos sobre teoria política. São Paulo: Loyola, 2002. . Conhecimento e Interesse. Rio de Janeiro: Zahar, 1982.

. Consciência moral e agir comunicativo. Rio de Janeiro: Tempo Brasileiro, 1989.

. Die Einbeziehung des Anderen - Studien zur politischen Theorie. Frankfurt. Suhrkamp, 1997.

. Direito e democracia: entre facticidade e validade. 2 Vols. Rio de Janeiro. Tempo Brasileiro, 1997.

. "Diskursethik - Notizen zu einem Begründungsprogram". In: HABERMAS, J. Moralbewusstsein und kommunikatives Handeln. Frankfurt: Suhrkamp, 1983.

. "Der demokratische Rechtsstaat - eine paradoxe Verbindung widersprüchlicher Prinzipien?" In:

HABERMAS, J. Zeit der Übergänge. Frankfurt: Suhrkamp, 2001.

. Erkenntniss und Interesse. Frankfurt: Suhrkamp, 1962.

. Faktizität und Geltung. Frankfurt: Suhrkamp, 1998.

. "O Estado democrático de direito - uma amarração paradoxal de princípios contraditórios?" In:

HABERMAS, J. Era das transições. Rio de Janeiro: Tempo Brasileiro, 2003.

. Sobre a Lógica das Ciências Sociais. São Paulo: Vozes, 2009.

. Zur Logik der Sozialwissenschaften. Frankfurt: Suhrkamp, 1982.

HONNETH, A. Kampf um Anerkennung. Frankfurt: Suhrkamp, 1992.

. Luta por Reconhecimento. São Paulo: Editora 34, 2002.

MacKENDRICK, K. Discourse, Desire, and Fantasy in Jürgen Habermas' Critical Theory. New York \& London: Routledge, 2008.

McCARTHY, T. "Practical Discourse: On the Relation of Morality to Politics". In: CALHOUN, C, (Ed). Habermas and the Public Sphere. Cambridge: The MIT Press, 1996.

MEEHAN, J (ed). Feminists Read Habermas. New York \& London: Routledge, 1995.

MELO, R. S. O uso público da razão como procedimento: pluralismo, discurso e democracia em Habermas. São Paulo: USP, 2004. Dissertação (Mestrado em Filosofia). Faculdade de Filosofia e Ciências Humanas, Universidade de São Paulo,

RAWLS, J. O A Theory of Justice. Cambridge. Harvard University Press, 1971.

Collected Papers. FREEMAN, S (ed), Cambridge: Harvard University Press, 1999.

. Liberalismo Político. São Paulo: Ática, 2000.

YOUNG, I. M. "Impartiality and Civil Public: Some Implications of Feminism Critiques of Moral and Political Philosophy”. In: BENHABIB, S. \& CORNELL, D (eds). Feminism as Critic. Minneapolis: University of Minnesota, 1987.

Recebido em: 18/09/2014

Aprovado para publicação em: 04/03/2015

\begin{tabular}{|c|c|c|c|c|c|}
\hline intuitio & $\begin{array}{c}\text { ISSN } \\
1983-4012\end{array}$ & Porto Alegre & Vol.8 $-\mathrm{N}^{\mathrm{o} .1}$ & $\begin{array}{c}\text { Junho } \\
2015\end{array}$ & p.246-260 \\
\hline
\end{tabular}

